\title{
Computational Method for Digital Khat Calligraphy Using Beta-Spline Curve Fitting
}

\author{
Normi Abdul Hadi ${ }^{*}$, Nur Sabrina Mohd Kamal and Hannani Nordin \\ Faculty of Computer and Mathematical Sciences, Universiti Teknologi MARA, 40450 Shah Alam, Selangor.
}

\begin{abstract}
Khat calligraphy is one of the most precious Islamic treasures since it has been existed thousands of years ago. Unfortunately, people nowadays seem to be less interested in learning khat and it can be seen that the appreciation towards mathematics is less because many of us did not realized that mathematics is involved behind a design of khat. Therefore, this study applies uniform cubic Betaspline curve fitting into the designing of Arabic fonts since it ensures the continuity of the curve where the curves generated are smoothly connected between each other. In order to design Arabic fonts, a rectangle shape needs to be produced first and then control points of designed fonts need to be identified. These points will generate knots that will provide better use in designing fonts. To find the knots, cubic Beta-spline curve fitting method is used to calculate the centre of the rectangle by applying the control points. From the rectangular model, the design of the Arabic font is applied by using centre of rectangle and connecting all rectangles produced into one graph in Maple software. The analysis of the results obtained shows the comparison of fonts produced depends on the uniform interval $t$, length and width of the rectangle as well as the angle of the pen's position. In conclusion, the cubic Beta-spline that has been used in this study plays an important role in the curve fitting purpose as the length $(L)$ and width $(W)$ of the rectangle as well as the shape parameters of $\beta_{1}=1$ and $\beta_{2}=0$ helps in controlling the shape of the model.
\end{abstract}

Keywords: CAGD, Beta-spline, Khat, Ethnomathematics

\section{INTRODUCTION}

By the definition of Arabic language, khat means writing or line. Khat calligraphy is divided into traditional khat and modern khat. Researchers found out that Muslims in the past have succeeded in producing more than 100 types of khat calligraphy such as Naskh, Thuluth, Muhaqqaq, Nastaliq and Riqa (Bilal et al., 2011). This study inspired by khat Thuluth based on its geometrical shape and suitable to be digitized. In addition, for writing the khat calligraphy they use Arabic fonts. Arabic font is an Arabic alphabet adapted for writing the Malay language (Nasrudin et al., 2008). There are 37 Arabic fonts that have been called as Jawi alphabets, however this study focused only on two alphabets which are $\varphi$ and $د$.
For the curve fitting for khat, there are several types of curves that can be used such as Bezier curve and B-spline curve. Barsky(1981) had introduced with a new term of curve called Beta-spline as the generalization of B-spline. Beta-spline curve tend to generate a smoother and more flexible shape as compared to the Bezier curve. It has control points with purpose to control the vertex movement of the curve (Barsky 1993). Two shape parameters called bias $\left(\beta_{1}\right)$, and tension $\left(\beta_{2}\right)$ were introduced to control the Beta-spline curve shape without changing the control points. The changes of $\left(\beta_{1}\right)$ and $\left(\beta_{2}\right)$ values will change the shapes and the positions of the Beta-spline curves. These parameters are the main advantages of Beta-spline over other curves besides the

\footnotetext{
*Corresponding author's e-mail: normi@fskm.uitm.edu.my
} 
guaranteed $G^{2}$ continuity. Beta-spline has been actively employed in generating 2-dimensional image such as font The Beta-spline curve appears to be a potential tool to be used to digitize the khat fonts.

This study is aiming to develop a computational method for digital khat calligraphy using Beta-spline curve. It includes constructing a rectangular shape from a point, fitting Beta-spline curve on Arabic font and fit the constructed rectangular the font. It is believed that the method developed can be used as a tool to assist the target of the study to write in khat calligraphy conveniently and at the same time can reduce the cost incurred. Thus, digital khat might attract new generations to learn and explore more about khat calligraphy in an interactive way of learning besides appreciating mathematics behind khat.

\section{MATERIALS AND METHODS}

The process of generating khat fonts are divided into three subprocesses: a consultation with an expert, the font generation using Beta-spline, and the khat calligraphy generation.

\section{A. A Consultation with An Expert}

An interview with one of khat calligrapher expert is done before the computational method development. This is to get the correct technique in writing khat, and to understand the aesthetic value in every khat calligraphy.

The chosen khat calligrapher is Ustaz Muhd Faizul Azmir bin Ramli (Azmir, n.d.). He has a degree in Usuluddin from Al-Azhar university, and a degree in Islamic calligraphy from Egypt. He has won several khat calligraphy competition such as Manifestasi Seni Khat Perdana 2017 ("Manifestasi Perdana Seni Khat 2017" 2017) and Pertandingan Seni Khat "Rukun Negara" (Ibnumubarak82, 2011). Currently, he is actively contributing in national and international khat calligraphy events as teacher and participant for example in Khat and Craft Course 2018 and 2019, organized by Islamic Art Museum, Malaysia.

The consultation gives idea about the correct writing technique of khat calligraphy such as the technique of holding the pen and the measurement technique for each letter. As an example, the angle of the pen for Thuluth khat is one-third of the pen point width, suits its name
Thuluth which means one-third. For measurement, the most referred method is by Ibnu Muqla, where measurement of all letters are based on dot, alif and circle (Kadhim \& Crimsh, 2017). However, only the holding pen technique is been considered in khat calligraphy development for this research.

\section{B. The Font Generation using Beta-Spline}

In this paper, two Arabic fonts are considered: ب and د . The fonts are manually generated using Beta-spline. Betaspline curve equations is given as,

$$
F(t)=[T][M][V]
$$

where $[T]=\left[t^{3} t^{2} t 1\right]$ is the knots with $0<t<1,[M]$ is the cubic Beta-spline basis function (Hadi et al. 2012) where,

[M]

$=\frac{1}{\delta}\left[\begin{array}{ccc}-2 \beta_{1}^{3} & 2\left(\beta_{2}+\beta_{1}^{3}+\beta_{1}^{2}+\beta_{1}\right) & -2\left(\beta_{2}+\beta_{1}^{2}+\beta_{1}+1, \text { (2 }\right. \\ 6 \beta_{1}^{3} & -3\left(\beta_{2}+2 \beta_{1}^{3}+2 \beta_{1}^{2}\right) & 3\left(\beta_{2}+2 \beta_{1}^{2}\right) \\ -6 \beta_{1}^{3} & 6\left(\beta_{1}^{3}-\beta_{1}\right) & 6 \beta_{1} \\ 2 \beta_{1}^{3} & \beta_{2}+4\left(\beta_{1}^{2}+\beta_{1}\right) & 2\end{array}\right)$

where,

$$
\delta=\beta_{2}+2 \beta_{1}^{3}+4 \beta_{1}^{2}+4 \beta_{1}+2
$$

and $[\mathrm{V}]$ is the control point matrix. Beta-spline is chosen due to its capability to produce smooth and accurate curve (Hadi et al., 2013).

The generated fonts of using Beta-spline are shown in the following Figure.

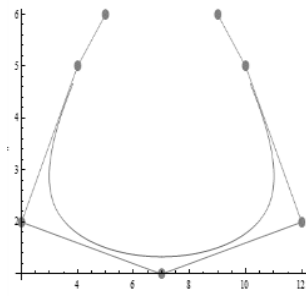

(a) Generated ب

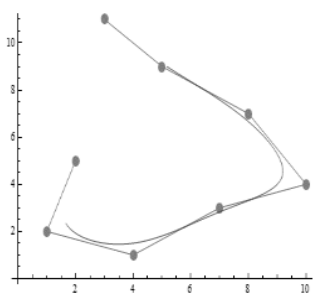

(b) Generated د
Figure 1: Generated $\varphi$ and د using beta-spline

In Figure 1, the control points are represented by dots, 
and the number of controls points are 7 and 8 for 4 and respectively.

\section{The font generation using khat calligraphy}

The boundary of $ب$ and د consist of curve points denoted as $\left(x_{i}, y_{i}\right)$ for the $i^{\text {th }}$ curve point. The khat calligraphy is generated by converting each $(x, y)$ to a rectangle shape. The methods used to model the rectangle shape are Pythagoras Theorem, Euclidean distance and slope as shown in Figure 2.

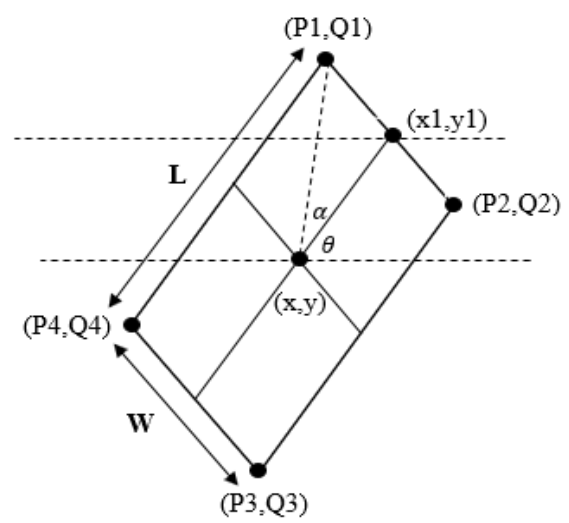

Figure 2: Rectangle shape

In Figure 2, a rectangle consists of some parameters: length of the rectangle $(L)$, width of the rectangle $(W)$ and the angle of the pen's position $(\theta)$. Point $(x, y)$ is the center of the rectangle, which is the curve point. All the calculation and plotting processes are done in Maple software.

\section{RESULTS AND DISCUSSIONS}

The generated rectangular shape using Beta-Spline curved fitting method is analysed by changing the values of parameters involved. The values of $t$ is fixed at $t=0.01$ such that 100 rectangles per curve segment are generated. The effect of various $L, W$ and $\theta$ are shown in Table 1 until Table 3.

Table 1. The generated $ب$ and $د$ for $W=\frac{L}{2}, \theta=\frac{\pi}{12}$,

Lenerated L vary

Table 1 shows the comparison on the length of the rectangle $(L)$ for $L=1.0$ and $L=3.0$ while both $W$ and $\theta$ are fixed at $\frac{L}{2}$ and $\frac{\pi}{12}$ respectively. It can be observed that font produced when $L=1.0$ is the thinner in terms of the font thickness compared to $L=3.0$.

Table 2. The generated $\varphi$ and $د$ for $L=3$ and $\theta=\frac{\pi}{12}$ and

$W$

Table 2 shows the comparison for the changes of the width of the rectangle for $W=\frac{L}{3}$ and $W=\frac{L}{9}$. It can be observed that, less value of $W$ has reduced the thickness of the font which can be seen in the lower part of the fonts. 


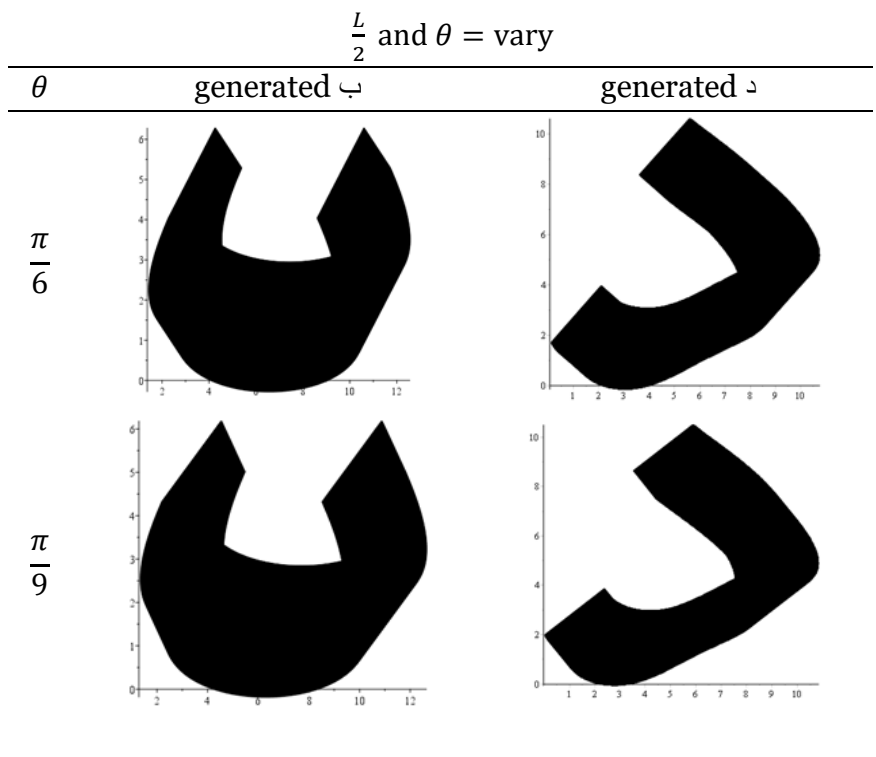

In Table 3, the value of the angle $(\theta)$ is changed. The angle in the study is depends on the position of the pen. It is shown that the inclination of the initial rectangles depends on the angle the initial rectangle. Higher $\theta$ value will make the rectangle lean to the left side and at the end of the font will become smoother where no sharp edge is detected.

From Table 1 to 3 , it can be concluded that pleasing shape of $\varphi$ and $د$ is produced for higher value $L$ of and lower values of $W$ and $\theta$. Another generated font is shown in Figure 3.

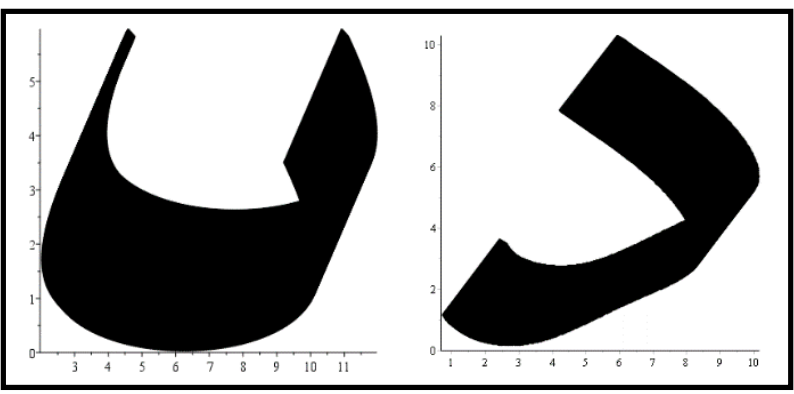

Figure 3. The generated $\varphi$ and $د$ for $L=3, W=\frac{L}{12}$ and $\theta=$ $\frac{\pi}{12}$

\section{SUMMARY}

This paper has developed a technique to represent a font in khat calligraphy form based on a rectangle shape. Some parameters are been considered in the khat calligraphy development such as the length $(L)$, the width $(W)$ and the angle $(\theta)$ of the rectangle. The boundary of the font is generated using Beta-spline to ensure the continuity of the curve. The developed technique will assist the font designer to manipulate the font shape as needed. For future direction, the more complicated font will be considered especially connected letters. Additionally, the font will be designed based on Ibnu Muqla theory has been discussed before.

\section{ACKNOWLEDGEMENT}

The authors would like to express sincere gratitude to the Universiti Teknologi MARA for funding the grant under LESTARI Grant (600-IRMI/DANA 5/3/LESTARI (0123/2016)). Lastly, much obliged to all the reviewers for the comments and suggestions. 


\section{REFERENCES}

Ahmed AbdulKadhim Crimsh, 2017. Analysis of The Calligraphy Design on Selected Quranic Phrases in The Blue Mosque Malaysia. University of Malaya, Kuala Lumpur.

Barsky, B.A., 1981. 'The beta-spline: a local representation based on shape parameters and fundamental geometric measure'. Univ. Utah.

Barsky, B.A., 1993. 'Rational beta-splines for representing curves and surfaces'. IEEE Comput. Graph. Appl. vol.13, pp.24-32.

Bilal, B., Siti Norul Huda, S.A., Khairudin, O., 2011. 'Generating an Arabic Calligraphy Text Blocks for Global Texture Analysis'. In: Proceeding of the International Conference on Advanced Science, Engineering and Information Technology 2011. Putrajaya, pp. 150-155.

Hadi, N.A., Ibrahim, A., Yahya, F., 2013. 'G 2 Beta-spline : An Ideal Surface Representation of Multi-Slice Medical Images'. In: IEEE 9th International Colloquium on Signal Processing and Its Applications. IEEE, Kuala Lumpur, pp. 8-10.

Hadi, N.A., Ibrahim, A., Yahya, F., Ali, J.M., 2012. '3Dimensional beta-spline wireframe of human face contours'. In: 2012 IEEE 8th International Colloquium on Signal Processing and Its Applications, CSPA 2012. IEEE, pp. 110-114.

Ibnumubarak82, 2011. Pertandingan Seni Khat "Rukun Negara” peringkat kebangsaan anjuran Perpustakaan Negara Malaysia [WWW Document]. <http://snikhatgallery.blogspot.com/2011/11/pertanding an-seni-khat-rukun-negara.html> (accessed 4.16.19).

Manifestasi Perdana Seni Khat 2017 [WWW Document], 2017. <http://www.iamm.org.my/manifestasi-perdanaseni-khat-2017/> (accessed 4.16.19).

Muhd Faizul Azmir, R., n.d. Faizul Azmir [WWW Document].

<https://www.facebook.com/faizul.azmir.33>

Nasrudin, M.F., Omar, K., Zakaria, M.S., Yeun, L.C., 2008. 'Handwritten cursive Jawi character recognition: A survey'. In: 2008 Fifth International Conference on Computer Graphics, Imaging and Visualisation. IEEE, pp. 247-256. 